\title{
Synthesis of Gallium Nitride and Related Oxides Via Ammonobasic Reactive Sublimation
} (ARS)

\author{
Luis Alberto Hernández-Hernández *, Jorge R. Aguilar-Hernández ${ }^{a}$, Francisco de Moure-Flores ${ }^{b}$, \\ Osvaldo de Melo-Pereira ${ }^{c}$, Concepción Mejía-García ${ }^{a}$, Francisco Cruz-Gandarilla ${ }^{a}$,

\section{Gerardo Contreras-Puente ${ }^{a}$} \\ ${ }^{a}$ Escuela Superior de Física y Matemáticas, Instituto Politécnico Nacional, Edificio No. 9, U.P.A.L.M., \\ San Pedro Zacatenco, C.P. 07738, Ciudad de México, México \\ ${ }^{b}$ Facultad de Química, Materiales-Energía, Universidad Autónoma de Querétaro, Querétaro C.P. \\ 09790, México \\ ${ }^{c}$ Facultad de Física, Universidad de La Habana, Colina Universitaria, 10400, La Habana, Cuba
}

Received: March 22, 2017; Revised: July 07, 2017; Accepted: August 27, 2017

\begin{abstract}
Ammonobasic reactive sublimation (ARS) is proposed as a novel method to synthesize GaN and related oxides. Results indicate that $\mathrm{GaN}$ growth occurs by a nitriding process of $\mathrm{Ga}$ and related oxides, establishing a direct dependence on $\mathrm{NH}_{4} \mathrm{OH}$ amount added as a primary chemical reactive. The samples were grown on p-type $\mathrm{Si}$ (111) substrates inside a tube furnace, employing GaN powder and $\mathrm{NH}_{4} \mathrm{OH}$. The characterizations of the samples were carried out by XRD, SEM, EDS and PL techniques, revealing the influence of $\mathrm{NH}_{4} \mathrm{OH}$ on the improvement of $\mathrm{GaN}$ synthesis and the enhancement of its optical and structural properties.
\end{abstract}

Keywords: Gallium nitride, Sublimation, X-ray diffraction, Photoluminescence, Gallium oxide

\section{Introduction}

Nitride semiconductors (III-N) properties make them an excellent choice for the development of electronic, optoelectronic and spintronic devices, due to their direct bandgap and high chemical, mechanical and thermal stability $^{1}$. Nowadays growth technologies to obtain gallium nitride $(\mathrm{GaN})$ thin films are based on epitaxial techniques, like metal-organic chemical vapor deposition (MOCVD) or molecular beam epitaxy (MBE). However, research based on non-epitaxial techniques, like reactive sputtering or ammonothermal reactions have been developed in order to achieve better results for the nitride semiconductor synthesis and enhancement of its properties.

Ammonothermal techniques are similar to our proposed method due to the employing of a furnace and use of ammonobasic compounds as precursors. However, these methods employed polycrystalline $\mathrm{GaN}$ as seeds in order to grow the material. Other specific growth parameters related to this method are, high ammonia $\left(\mathrm{NH}_{3}\right)$ pressure in the system (between 150-500 MPa), temperature in the range of 500-600 ${ }^{\circ} \mathrm{C}$ and a long growth time that could take several hours $^{2-8}$. Optimization of the system in order to improve the growth rate and purity are in progress ${ }^{9-11}$.

Santana et al. ${ }^{12,13}$ demonstrated that GaN can be grown via the sublimation of GaN powders without any additional source of nitrogen $(\mathrm{N})$, but the results indicate that the samples are nitrogen deficient. Moreover, in that work the growth temperature was limited by the use of a graphite

*e-mail: schwarzerengelxv@hotmail.com plate heated by infrared lamps. Taking into account those issues, we propose alternatively, the addition of ammonium hydroxide $\left(\mathrm{NH}_{4} \mathrm{OH}\right)$ as a compensation source of $\mathrm{N}$ and the use of a tube furnace for a better control of the temperature needed to synthesize GaN. Ammonium hydroxide has been selected due to its relatively easy handling and low-cost compared to common nitrogen sources of $\mathrm{NH}_{3}$ and $\mathrm{N}_{2}$ that require complementary and complex systems.

The growth of GaN thin films by the Ammonobasic Reactive Sublimation (ARS) is reported, this method is proposed as an alternative low-cost route employing a tube furnace. The ARS method is based on a sublimation technique that has high growth rate compared to ammonothermal techniques; it requires a low reactive ambient pressure and few precursors. To our knowledge few groups in the world are processing GaN by sublimation (either close spaced sublimation or closed space vapor transport), which in our case allowed the growth of GaN material, in spite of the fact that these techniques represent a fast non-thermal-equilibrium process, as compared to expensive techniques like MBE or MOCVD. The physical properties of the GaN synthesized by this process are improved by the employment of $\mathrm{NH}_{4} \mathrm{OH}$ in comparison with previous results ${ }^{12,13}$.

\section{Experimental}

Samples were grown on p-type Si (111) substrates, employing GaN powder (99.99\% purity) and $\mathrm{NH}_{4} \mathrm{OH}$ as precursors, all of them contained inside a graphite cell. 
The scheme of the graphite cell is shown in Fig. 1, this is composed by two pieces: 1) a substrate holder and powder container and 2) a cap. Holder and cap are tightly closed in a screw and nut configuration, these pieces join together to form a semi-hermetic container.

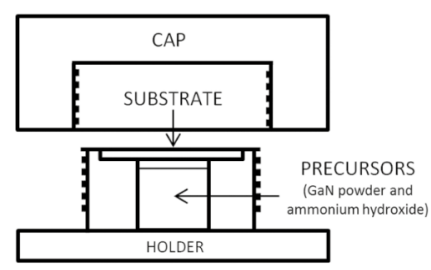

LATERAL VIEW

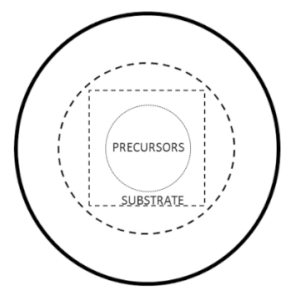

TOP VIEW
Figure 1. Scheme of the graphite cell. Semi-hermetic container constituted of two pieces: 1) a substrate holder and powder container and 2) a cap.

Ammonium hydroxide was added with an eyedropper and the amount varied in order to evaluate its function as nitrogen compensation source. However, the concentration was not accurately determined due to an apparent $\mathrm{GaN}$ permeability property and the high volatility of $\mathrm{NH}_{4} \mathrm{OH}$.

Concentrations can be estimated as follows. The holder has a volume of $\sim 0.27 \mathrm{~cm}^{3}$ that can contain a mixture of $\mathrm{GaN}$ powder $(\sim 150 \mathrm{mg})$ and $\mathrm{NH}_{4} \mathrm{OH}$, close to the substrate surface $(<1 \mathrm{~mm})$. The samples are labeled according to the $\mathrm{NH}_{4} \mathrm{OH}$ amount employed, considering that each drop has a volume $\sim 0.05 \mathrm{ml}$, the corresponding labels are presented in Table 1.

Table 1. Label of samples according to the amount of $\mathrm{NH}_{4} \mathrm{OH}$.

\begin{tabular}{lcc}
\hline Sample & $\mathrm{NH}_{4} \mathrm{OH}(\mathrm{ml})$ & $\mathrm{GaN}(\mathrm{mg})$ \\
\hline S-0.10 & 0.10 & 150 \\
S-0.15 & 0.15 & 150 \\
S-0.20 & 0.20 & 150 \\
\hline
\end{tabular}

The material growth was carried out inside a tube furnace, without any vacuum system or gas flow. The growth temperature was $1200^{\circ} \mathrm{C}$ and the growth time 10 minutes. The growth time is shorter than the growth time employed with other techniques, which were of at least 1 hour ${ }^{14,15}$.

Structural analysis was carried out by X-ray diffraction (XRD) operating in grazing angle with a $\mathrm{Cu}-\mathrm{K}_{\alpha}$ radiation source (Bruker D8 advance). Morphology was examined by scanning electron microscopy (SEM, JEOL JSM-6300) equipped with an energy dispersive X-Ray spectrometer (EDS, Bruker XFlash 5010). Photoluminescence (PL) properties at room temperature were measured employing a $\mathrm{He}: \mathrm{Cd}$ laser $(\lambda=325 \mathrm{~nm})$ as excitation source, a double monochromator (1403-SPEX) and a photomultiplier detector (RCA-C310334).

\section{Results and Discussion}

\subsection{Structural, morphology and chemical analysis}

The XRD patterns of the samples, S- 0.10 and S- 0.15 , are shown in Fig. 2 (a) and (b) respectively. For these samples, diffraction peaks corresponded to the $\beta-\mathrm{Ga}_{2} \mathrm{O}_{3}$ phase (JCPDS ${ }^{\mathrm{I}}$ Card No. 041-1103) while for sample S-0.20, the peaks are clearly associated with a mixture of $\beta-\mathrm{Ga}_{2} \mathrm{O}_{3}$ and wurtzite GaN (indexed according to JCPDS Card No. 076-0703), as shown in Fig. 3.

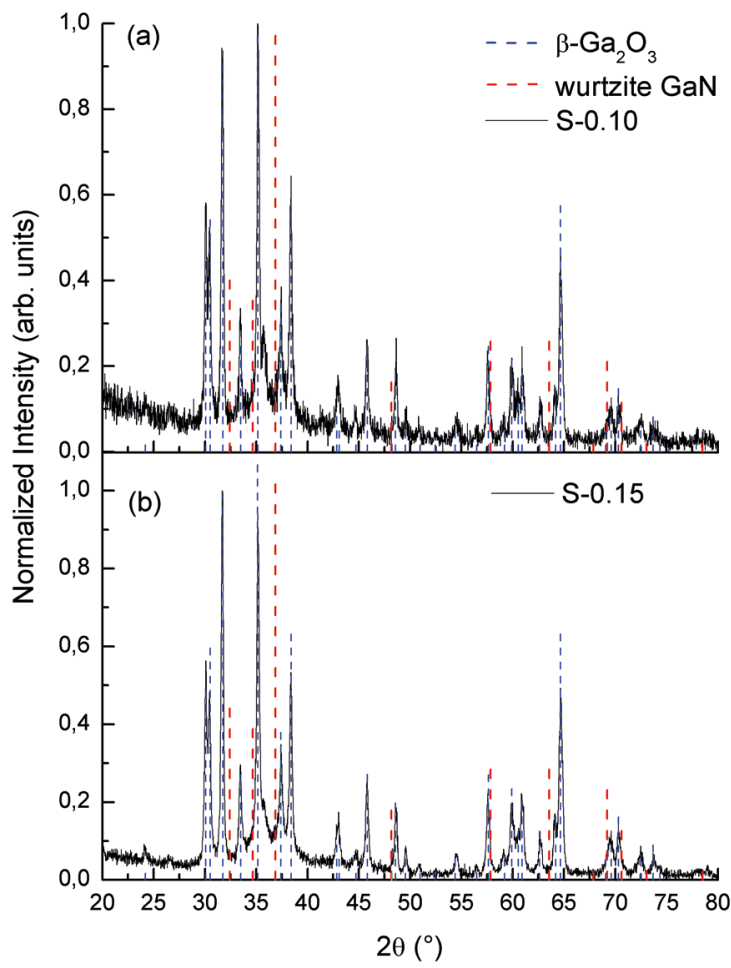

Figure 2. XRD diffraction patterns of samples: (a) S-0.10 and (b) $\mathrm{S}-0.15$. The patterns of both samples are quite similar; however, sample S-0.15 has improved its crystallinity as compare to S-0.10. In sample $\mathrm{S}-0.15$, the background intensity as well as the noise signal decreases.

A Rietveld analysis was performed in order to determine the phase fractions of $\beta-\mathrm{Ga}_{2} \mathrm{O}_{3}$ and $\mathrm{GaN}$ present in sample $\mathrm{S}-0.20$. This analysis was carried out by employing the crystallographic information for the compounds GaN (ICSD ${ }^{\text {II }}$ 98-002-5676) and $\beta-\mathrm{Ga}_{2} \mathrm{O}_{3}$ (ICSD 98-003-4243) using the MAUD program ${ }^{\mathrm{III}}$. Results of this study are presented in Table 2.

The SEM images of the samples are shown in Fig. 4 to 6. As it can be seen, morphology of samples S-0.10 (Fig. 4) and S-0.15 (Fig. 5) are quite similar, both of them exhibit the growth of some wire-like structures, which appear to be

\footnotetext{
I ICDD-PDF2 International Center for Diffraction Data - Powder Diffraction Patterns http://www.icdd.com

II ICSD - Inorganic Crystal Structure Database https://www.fiz-karlsruhe.de/en/leistungen/kristallographie/icsd.htm

III Materials Analysis Using Diffraction (MAUD) program http://maud.radiographema.com
} 


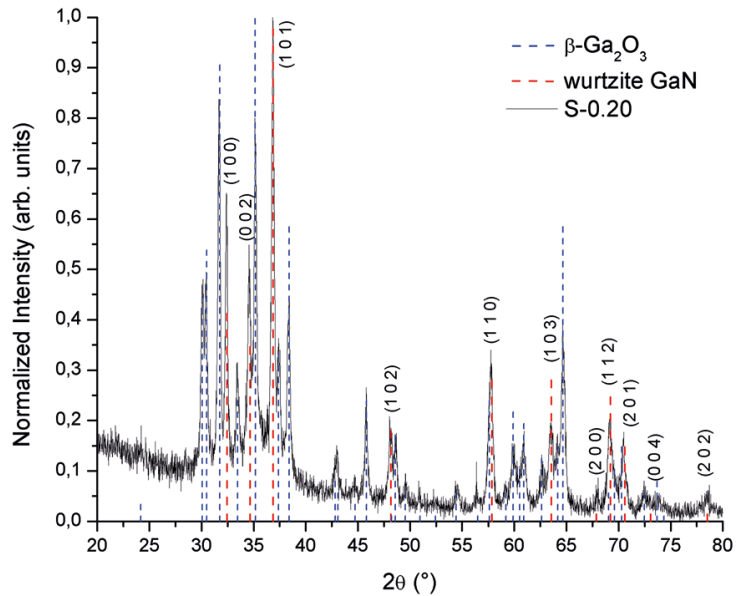

Figure 3. XRD diffraction pattern of sample S-0.20. Contrary to samples S-0.10 and S- 0.15 , the phase of GaN is completely identified and indexed; this evidences the influence of $\mathrm{NH}_{4} \mathrm{OH}$ as a synthesis promoter of $\mathrm{GaN}$ by the ARS method.

Table 2. $\mathrm{GaN}$ and $\beta-\mathrm{Ga}_{2} \mathrm{O}_{3}$ phase fractions in sample S- 0.20 according to Rietveld analysis.

\begin{tabular}{lcc}
\hline & Weight fraction & Volume fraction \\
\hline $\mathrm{GaN}$ & 0.693 & 0.665 \\
$\beta-\mathrm{Ga}_{2} \mathrm{O}_{3}$ & 0.307 & 0.335 \\
\hline
\end{tabular}

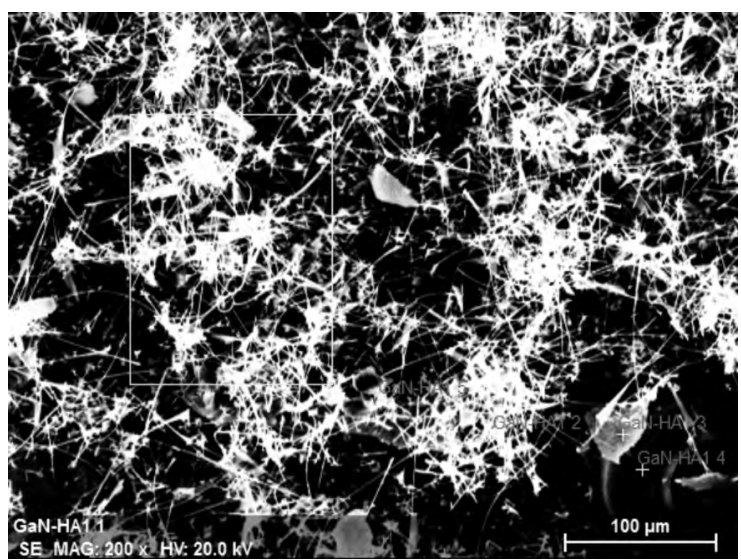

Figure 4. SEM image of sample S-0.10. An irregular morphology is observed, some particles and wire-like structures were grown on the substrate surface.

grouped by nodes or nucleation points. However, sample S-0.20 (Fig. 6) is completely different showing an agglomerate of irregular particles with many porous between them.

The average concentration of gallium and nitrogen according to EDS analysis for each sample are summarized in Table 3. It can be observed that $\mathrm{S}-0.10$ and $\mathrm{S}-0.15$ samples are non-stoichiometric, while S- 0.20 sample is almost stoichiometric.

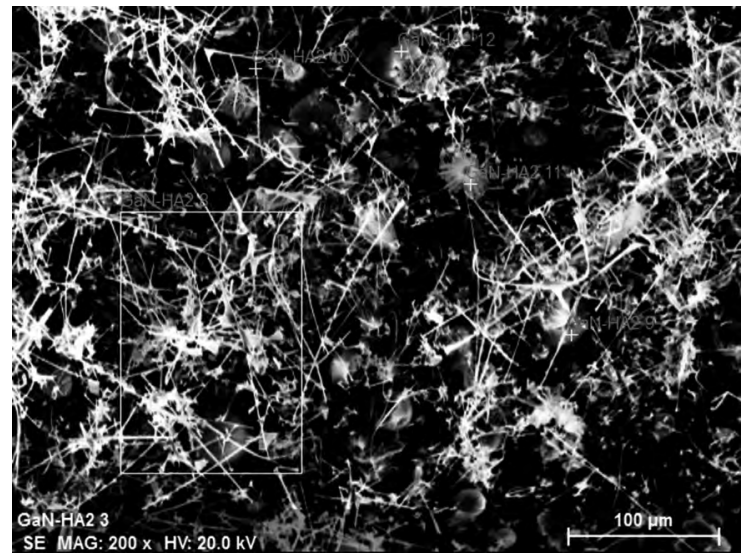

Figure 5. SEM image of sample S- 0.15 . The morphology is similar to sample S-0.10; however, the density of wire-like structures in samples S- 0.15 is higher than that in $\mathrm{S}-0.10$.

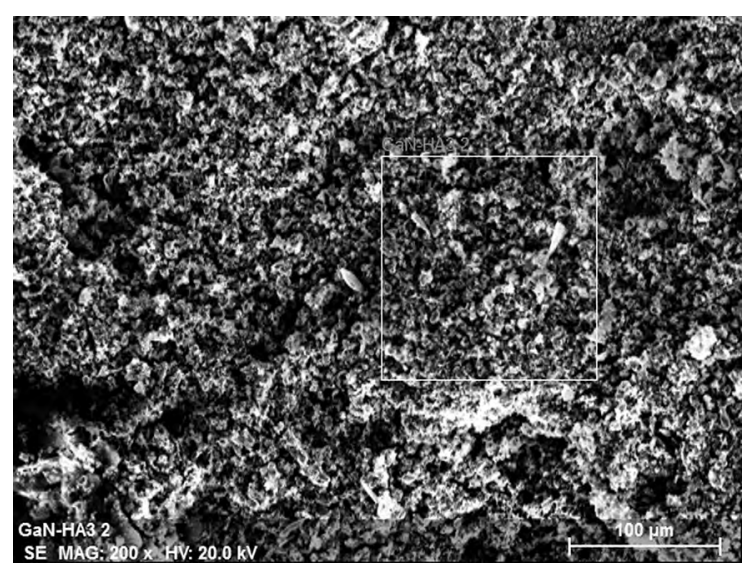

Figure 6. SEM image of sample S-0.20. Morphology of this is completely different, the density of wire-like structures appears to be null compared with samples S- 0.10 and S- 0.15 .

\subsection{Photoluminescence}

The PL spectra obtained for samples S-0.10 and S0.20 exhibit a broad emission band from $\sim 1.8$ to $3.2 \mathrm{eV}$, having two clear maxima. Moreover, in the case of sample S-0.15 a shoulder on the high photon energy side can be also distinguished, which indicates another PL emission at high energy, above $3.0 \mathrm{eV}$. In order to assign the corresponding emissions, an iterative fitting process of the PL spectra was performed. The normalized room temperature photoluminescence spectrum of each GaN film and its related deconvoluted bands are shown in Fig.7. Two strong emission bands could be assigned, the first in the green region with a maximum at $2.37 \mathrm{eV}$, and the second one in the blue region with a maximum located between $2.75-2.85 \mathrm{eV}$ depending on the sample. According to literature, the first emission labeled GL-2, is related to Ga-rich wurtzite GaN samples ${ }^{16}$, while 
Table 3. Atomic concentration of Ga and N, determined by EDS, in samples S-0.10, S- 0.15 and S- 0.20

\begin{tabular}{lcc}
\hline & Ga (at. \%) & N (at. \%) \\
\hline S-0.10 & 81.46 & 18.54 \\
S-0.15 & 67.01 & 32.99 \\
S-0.20 & 48.04 & 51.96 \\
\hline
\end{tabular}

the second is related to $\beta-\mathrm{Ga}_{2} \mathrm{O}_{3}$ nanostructures ${ }^{17}$; this means that a higher concentration of $\mathrm{Ga}$ in the samples is related to an increase in $\beta-\mathrm{Ga}_{2} \mathrm{O}_{3}$ phase growth. Additionally, sample $\mathrm{S}-0.15$ shows a low intensity band around $3.04 \mathrm{eV}$ related to the blue shifted emission that is associated with GaN samples contaminated with carbon $(\mathrm{C} \text {-doped } \mathrm{GaN})^{16}$.

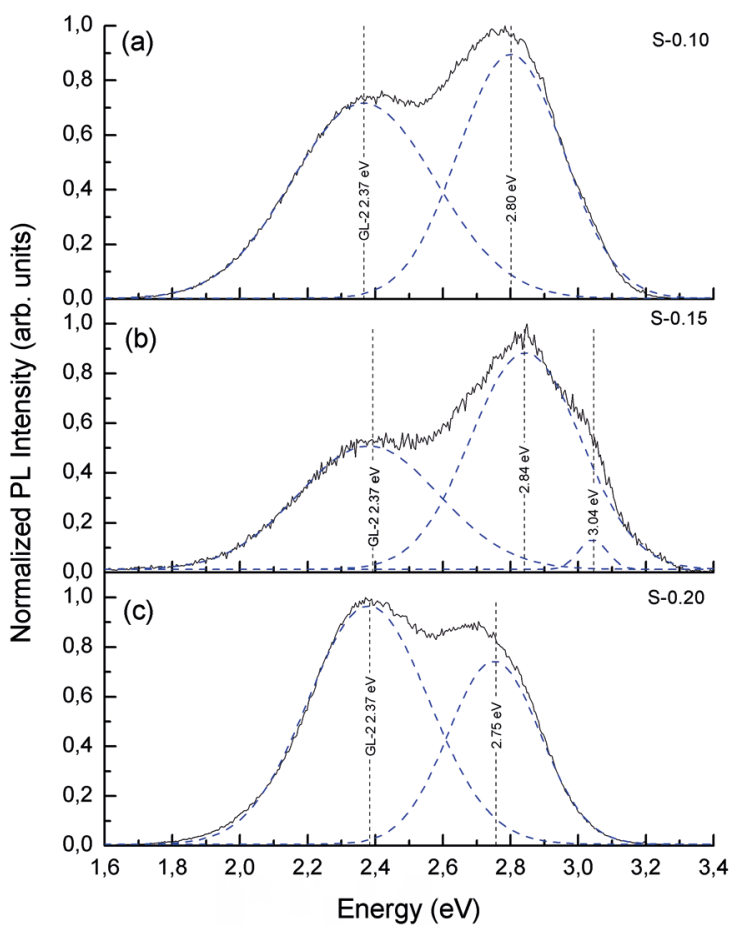

Figure 7. Normalized PL spectrum (black line) and its related deconvoluted bands (blue dash line) for samples: (a) S-0.10, (b) S-0.15 and (c) S-0.20. PL spectra of S- 0.10 and S- 0.15 are similar between them, which primary emission is related to $\beta-\mathrm{Ga}_{2} \mathrm{O}_{3}$ nanowires, but $\mathrm{S}-0.15$ also has a low intensity emission band related to $\mathrm{C}$-doped $\mathrm{GaN}$ at $3.04 \mathrm{eV}$. However, the primary emission band in S-0.15 PL spectrum is the GL-2, contrary to samples S- 0.10 and S- 0.15 .

\subsection{Discussion}

Samples S-0.10 and S-0.15 have similar properties, XRD indicates the growth of polycrystalline $\beta-\mathrm{Ga}_{2} \mathrm{O}_{3}$ and SEM images exhibit the grow of wire-like structures over the sample surface. However, the density of these structures in $\mathrm{S}-0.10$ is less than that in $\mathrm{S}-0.15$. This can be related to the nitrogen concentration in the samples, suggesting a direct relation between the growth kinetics and the nitrogen concentration.
We considered that $\mathrm{GaN}$ small crystals act as nucleation centers for $\beta-\mathrm{Ga}_{2} \mathrm{O}_{3}$ structures; then a higher nitrogen concentration provides a higher density of $\mathrm{GaN}$ nucleation centers and the growth rate of $\beta-\mathrm{Ga}_{2} \mathrm{O}_{3}$ structures should increase. As we mention before, this sort of gallium oxide structures exhibit blue emission luminescence which is the principal emission in these samples. However, although there are no peaks in XRD patterns related to GaN, there must be some GaN growth on the surface which could be associated with the mentioned GL-2 emission.

The S-0.20 sample presents a very different surface morphology; notably there is an apparent absence of wirelike structures. The XRD pattern indicates the presence of polycrystalline $\mathrm{GaN}$ and $\beta-\mathrm{Ga}_{2} \mathrm{O}_{3}$. Therefore we assume that the top layers on the surface correspond to a $\beta-\mathrm{Ga}_{2} \mathrm{O}_{3}$ phase, while the inner layers beneath the surface are GaN. The increase of $\mathrm{NH}_{4} \mathrm{OH}$ modifies the growth kinetics, implying a different surface morphology. The EDS results indicate a higher concentration of nitrogen in this sample, corresponding to XRD results. Additionally, the PL spectrum shows that the GL-2 band has a higher intensity than the band at 2.75 $\mathrm{eV}$, contrary to samples S-0.10 and S-0.15.

Taking into account the previous considerations, we propose a general mechanism of growth for GaN synthesis via $\mathrm{NH}_{4} \mathrm{OH}$ reactive sublimation. First, the ammonium hydroxide releases hydrogen due to the increase of temperature, the ammonium molecules start to dissociate into different complexes as $\mathrm{NH}_{3}, \mathrm{NH}_{2}, \mathrm{NH}$ and $\mathrm{N}_{2}, \mathrm{~N}, \mathrm{H}_{2}, \mathrm{H}^{14}$; assuming that there is an increase of the pressure inside of the semihermetic graphite cell as the temperature increases. This process will continue until the temperature reaches $1175^{\circ} \mathrm{C}$, approximately, when the $\mathrm{GaN}$ begin to dissociate, leading to a second increase of the pressure into the chamber related to the release of nitrogen. Under these conditions of temperature and pressure, we assume that the vapor of water can reach a critical point and start to dissociate providing additional $\mathrm{H}$ and $\mathrm{O}$. We consider that the effective growth time to be about 10 minutes after the moment when the temperature reaches $1200^{\circ} \mathrm{C}$. At this stage of the growth, Ga vapors are condensed on the Si surface and several reactions could take place, which involves the interactions between the $\mathrm{C}$ of the cell, the Si substrate and the Ga film already deposited on it, and also with the complexes of nitrogen, hydrogen and oxygen present in the growth cell.

According to our proposed synthesis process and taking into consideration similar reactions to those reported for the GaN synthesis by Nabi et al. ${ }^{15}$, the reaction stages inside the cell may be assumed as follows. Since the affinity of Ga and $\mathrm{O}$ is greater than that of $\mathrm{Ga}$ and $\mathrm{N}$, we propose that after $\mathrm{GaN}$ dissociates $\beta-\mathrm{Ga}_{2} \mathrm{O}_{3}$ is synthesized, then this compound react in two ways: 
1a) $\beta-\mathrm{Ga}_{2} \mathrm{O}_{3}$ reacts with $\mathrm{C}$ of the cell giving rise to a reaction that provides another kind of gallium oxide $\left(\mathrm{Ga}_{2} \mathrm{O}\right)$ and carbon monoxide (CO):

$$
\mathrm{Ga}_{2} \mathrm{O}_{3}+2 \mathrm{C} \rightarrow \mathrm{Ga}_{2} \mathrm{O}(g)+2 \mathrm{CO}(g)
$$

1b) $\beta-\mathrm{Ga}_{2} \mathrm{O}_{3}$ reacts simultaneously with the ammonia released after the dissociation of the ammonium hydroxide and the $\mathrm{C}$ of the cell, giving rise to $\mathrm{GaN}$ and $\mathrm{CO}$ :

$$
\mathrm{Ga}_{2} \mathrm{O}_{3}+2 \mathrm{NH}_{3}(g)+3 \mathrm{C} \rightarrow 2 \mathrm{GaN}+3 \mathrm{CO}(g)+3 \mathrm{H}_{2}(g)
$$

The $\mathrm{Ga}_{2} \mathrm{O}$ produced during the reaction 1a), could react with the other products released during the previous reactions in different ways:

2a) Due to a reduction process

$$
G a_{2} O(g)+C O(g) \rightarrow G a(g)+G a(l)+C O_{2}
$$

2b) By the reaction with the $\mathrm{N}$ present inside the cell

$$
\mathrm{Ga}_{2} \mathrm{O}(g)+3 \mathrm{~N} \rightarrow 2 \mathrm{GaN}+\mathrm{NO}
$$

According to the aforementioned reactions, we assumed that the graphite cell also reacts with precursors, in the same way as $\mathrm{C}$ reacts in the ammonothermal process. This will reduce the $\beta-\mathrm{Ga}_{2} \mathrm{O}_{3}$ and stimulate $\mathrm{GaN}$ synthesis. On other hand $\mathrm{NH}_{3}$ and $\mathrm{N}$ are generated by the dissociation of $\mathrm{NH}_{4} \mathrm{OH}$ and $\mathrm{GaN}$.

The results indicate that sublimation is a viable route in order to synthesized GaN films. Our method proposed to use ammonium hydroxide as a nitrogen compensation source in order to achieve better films and improve its properties. Contrary to ammonothermal methods that employ GaN seeds to grow the samples, we use silicon ( $\mathrm{Si}$ ) substrates. These ammonothermal methods needs high ammonia pressures $(>100 \mathrm{MPa})$ while we use only a small amount of ammonium hydroxide $(<0.5 \mathrm{ml})$. We point out that ammonia is extremely caustic and hazardous compared to ammonium hydroxide; the handling of the reactive precursors and reaction products released during the growth process implies additional systems that increase the cost of the ammonothermal processes, on the other hand, the effective growth time of these methods is longer than $1 \mathrm{hr}$ while the one we propose takes short times, of the order of 10 minutes only.

\section{Conclusions}

We can conclude that $\mathrm{GaN}$ film synthesis via ammonobasic reactive sublimation (ARS) is a promising low cost method because it increases the growth rate of polycrystalline $\mathrm{GaN}$ by a nitriding process of $\mathrm{Ga}$ and its related oxides; it requires the employing of $\mathrm{GaN}$ powder and $\mathrm{NH}_{4} \mathrm{OH}$ as precursors.
It was possible to increase $\mathrm{GaN}$ growth while decreasing the $\beta-\mathrm{Ga}_{2} \mathrm{O}_{3}$ fraction with increasing $\mathrm{NH}_{4} \mathrm{OH}$ concentration in the cell. The method does not require the assistance of conventional nitrogen compensation sources, like $\mathrm{N}_{2}$ and $\mathrm{NH}_{3}$ fluxes at high pressure and with long exposure times. Contrary to ammonothermal methods, the ARS method requires only low concentrations of precursors $\mathrm{GaN}(<0.200 \mathrm{~g})$ and $\mathrm{NH}_{4} \mathrm{OH}(<0.5 \mathrm{ml})$ and short growth times $(10 \mathrm{~min})$. The XRD, SEM, EDS and PL measurements evidence the improvement of the optical and structural properties as the concentration of $\mathrm{NH}_{4} \mathrm{OH}$ increases. Physical properties and growth rates of GaN films synthesized by ARS are improved compared with previous results obtained by close space vapor transport ${ }^{12,13}$. Additionally, an intense white PL emission at room temperature was observed for all the films due to the contributions of the GL-2 band associated with GaN, and the blue band related to the $\beta-\mathrm{Ga}_{2} \mathrm{O}_{3}$ nanostructures.

\section{Acknowledgements}

This work was supported by CONACyT-SENER [project number 151076]; CeMIE-Sol [project number P37]; and the IPN. [SIP's project number 20160436, 20161872].

We acknowledge to Dr. Ángel Guillén Cervantes from CINVESTAV for his collaboration with the SEM and EDS measurements.

We acknowledge to Dr. Maria de los Ángeles Hernández Pérez from ESIQIE-IPN for his collaboration with the XRD measurements.

We acknowledge to Professor A. D. Compaan from Lucintech Inc. for the fruitful comments on this work.

\section{References}

1. Pankove JI. GaN: from fundamentals to applications. Materials Science and Engineering: B. 1999;61-62:305-309.

2. Wang B, Callahan MJ, Rakes KD, Bouthillette LO, Wang SQ, Bliss DF, et al. Ammonothermal growth of GaN crystals in alkaline solutions. Journal of Crystal Growth. 2006;287(2):376380 .

3. Hashimoto T, Wu F, Saito M, Fujito K, Speck JS, Nakamura S Status and perspectives of the ammonothermal growth of GaN substrates. Journal of Crystal Growth. 2008;310(5):876-880.

4. Ehrentraut D, Kagamitani Y, Fukuda T, Orito F, Kawabata S, Katano K, et al. Reviewing recent developments in the acid ammonothermal crystal growth of gallium nitride. Journal of Crystal Growth. 2008;310(17):3902-3906.

5. Dwilinski R, Doradzinski R, Garczynski J, Sierzputowski L, Kucharski R, Zajac M, et al. Recent achievements in AMMONObulk method. Journal of Crystal Growth. 2010;312(18):24992502 .

6. Yoshikawa A, Ohshima E, Fukuda T, Tsuji H, Oshima K. Crystal growth of $\mathrm{GaN}$ by ammonothermal method. Journal of Crystal Growth. 2004;260(1-2):67-72. 
7. D'Evelyn MP, Hong HC, Park DS, Lu H, Kaminsky E, Melkote RR, et al. Bulk GaN crystal growth by the highpressure ammonothermal method. Journal of Crystal Growth. 2007;300(1):11-16.

8. Dwilinski R, Doradzinski R, Garczynski J, Sierzputowski LP, Puchalski A, Kanbara Y, et al. Bulk ammonothermal GaN. Journal of Crystal Growth. 2009;311(10):3015-3018.

9. Pimputkar S, Speck JS, Nakamura S. Basic ammonothermal $\mathrm{GaN}$ growth in molybdenum capsules. Journal of Crystal Growth. 2016;456:15-20.

10. Malkowski TF, Pimputkar S, Speck JS, DenBaars SP, Nakamura $\mathrm{S}$. Acidic ammonothermal growth of gallium nitride in a linerfree molybdenum alloy autoclave. Journal of Crystal Growth. 2016;456:21-26.

11. Pimputkar S, Kawabata S, Speck JS, Nakamura S. Improved growth rates and purity of basic ammonothermal GaN. Journal of Crystal Growth. 2014;403:7-17.

12. Santana-Rodríguez G, de Melo O, Aguilar-Hernández J, Mendoza-Pérez R, Monroy BM, Escamilla-Esquivel A, et al. Photoluminescence Study of Gallium Nitride Thin Films
Obtained by Infrared Close Space Vapor Transport. Materials (Basel). 2013;6(3):1050-1060.

13. Santana-Rodríguez G, de Melo O, Aguilar-Hernández J, Mendoza-Pérez R, Monroy BM, Escamilla-Esquivel A, et al. Close space vapor transport of gallium nitride in vacuum. Materials Letters. 2013;96:34-37.

14. Nabi G, Cao C, Hussain S, Khan WS, Mehmood T, Usman $\mathrm{Z}$, et al. Photoluminescence and hydrogen storage properties of gallium nitride hexagonal micro-bricks. Materials Letters. 2012;79:212-215.

15. Nabi G, Cao C, Khan WS, Hussain S, Usman Z, Safdar M, et al. Synthesis, characterization, growth mechanism, photoluminescence and field emission properties of novel dandelion-like gallium nitride. Applied Surface Science. 2011;257(23):10289-10293.

16. Reshchikov MA, Morkoç H. Luminescence properties of defects in GaN. Journal of Applied Physics. 2005;97(6):06131.

17. Wu XC, Song WH, Huang WD, Pu MH, Zhao B, Sun YP, et al. Crystalline gallium oxide nanowires: intensive blue light emitters. Chemical Physics Letters. 2000;328(1-2):5-9. 